\title{
Habilidades sociais, interação social e a inclusão escolar de uma criança cega
}

\author{
Marina Pereira de Souza* \\ Priscila Alcântara Bezerra Silva** \\ Maria Luiza Pontes de França-Freitas*** \\ Graziela Maria da Silva Gatto****
}

\section{Resumo}

O presente artigo tem os seguintes objetivos: (a) analisar o repertório de habilidades sociais e a inclusão escolar de uma criança cega; (b) caracterizar o repertório de habilidades sociais dessa criança; (c) caracterizar a interação social da criança cega no contexto da educação inclusiva. Para atender a esses objetivos foi realizada uma pesquisa qualitativa de delineamento descritivo, através de multimétodos, com estudo de caso com uma criança com cegueira total, de 11 anos de idade, aluna de uma escola regular do sistema público de ensino. Foram realizados registros em vídeo da interação social da criança cega no contexto escolar. Os pais e professores responderam ao inventário SSRS-BR ${ }^{2}$, utilizado para caracterização do repertório de habilidades sociais da criança. Os resultados obtidos apontaram que a criança apresentou um repertório de habilidades sociais médio inferior, com os menores escores relacionados às habilidades de desenvoltura social, assertividade, cooperação e afetividade. Responsabilidade foi a classe de habilidade social mais desenvolvida. Verificou-se que a criança interagia com maior frequência com as professoras e com os colegas da sala de recursos e recusava as iniciativas de interaçáo das crianças videntes. A criança apresentou déficits em algumas classes de habilidades sociais, o que possivelmente interferiu na sua relaçáo com os colegas e consequentemente no processo de inclusão. Nesse sentido é importante que estudos mais aprofundados sejam desenvolvidos com crianças deficientes visuais para que se ampliem a formulação de práticas pedagógicas, que possam estimular o desenvolvimento de habilidades sociais e a promoção de interaçôes sociais satisfatórias no contexto escolar.

Palavras-chave: Habilidades sociais; Criança cega; Inclusão escolar.

\footnotetext{
* Pós Graduanda em Terapia Cognitivo Comportamental, Estácio Fase, Aracaju, Sergipe, Brasil.

** Pós Graduanda em Terapia Cognitivo Comportamental, Estácio Fase, Aracaju, Sergipe, Brasil.

*** Professora doutora da Universidade Federal do Rio Grande do Norte, Natal, Rio Grande do Norte, Brasil.

**** Professora da Faculdade Pio Décimo, Aracajú, Sergipe, Brasil.
} 


\section{Social skills, social interaction and school inclusion of a blind child}

\section{Abstract}

This article has the following objectives: (a) analyze the social skills and school inclusion of a blind child; (b) characterize the social skills of that child; (c) characterize the social interaction of blind children in the context of inclusive education. To meet these objectives was carried a qualitative descriptive research design, by multi methods, with case study of a child with total blindness, 11-year-old student at a regular school in the public school system. Video recordings were made of the social interaction of blind children in the school context. Parents and teachers completed the SSRS-BR ${ }^{2}$ inventory, used for characterizing the social skills of the child. The results obtained indicate that the child has a repertoire of social skills below average, with lower scores related to social resourcefulness skills, assertiveness, cooperation and affection. Responsibility as the class of more developed social skills. It was observed that children interact more frequently with teachers and with colleagues in the resource room and reject initiatives interaction of child seers. The child has deficits in some classes of social skills which ultimately interfere with your relationship with colleagues and consequently in the inclusion process. In this sense it is important that larger studies are developed with visually impaired children, to which extend the formulation of pedagogical practices which encourage the development of skills and the promotion of social interactions satisfactory in the school context.

Keywords: Social skills; Blind child; School inclusion.

\section{Introdução}

Falar de deficiência visual é perpassar por todo um processo de transformaçóes sociais, culturais, estigmas e preconceitos que permeiam a história da humanidade e das pessoas com diferentes tipos de deficiência, sejam essas, sensoriais, físicas ou mentais. A deficiência visual refere-se a "uma limitação das formas de apreensão do mundo externo - a visão" (Nunes, Lomônaco, 2010, p. 56) e inclui dois grupos de condiçốes distintas: cegueira e baixa visão.

De acordo com o Ministério da Educação (2001), a cegueira está relacionada à perda total da percepçáo visual até a ausência de projeção de luz, enquanto a baixa visão refere-se a uma alteração na capacidade funcional da visão, decorrente de inúmeros fatores que interferem no desempenho visual do indivíduo. Nesse contexto, faz-se necessário mencionar Orrico, Canejo, Fogli (2009, p.121), os quais enfatizam que "independentemente da causa ou do período em que a deficiência visual se estabelece, inevitavelmente, interfere em diferentes habilidades e atividades cotidianas do indivíduo". Porém, tais autores ressaltam que com atendimento educacional adequado e acesso a programas e serviços especializados de reabilitação, a falta, perda ou diminuição acentuada da visão não significará a impossibilidade de uma vida independente, plena e produtiva. 
Existem instrumentos e procedimentos que são importantes para reabilitação e inserção social desses indivíduos, como cita Nobre et. al. (2006, p. 256) ao afirmar que "são reconhecidas como atividades essenciais para reabilitação de pessoas portadoras de deficiência visual a orientação e mobilidade, atividades da vida diária, educação básica e profissionalização". Esses autores ainda destacam a importância do desenvolvimento de atividades que promovam eficiência visual e utilização de recursos ópticos e não ópticos que se adequem as necessidades de cada indivíduo.

Deste modo, entender a deficiência é compreender as possibilidades de cada indivíduo, visto que atualmente, apesar das diversas dificuldades que as pessoas com algum tipo de deficiência apresentam, com o apoio e estímulos adequados, eles conseguem desenvolver suas potencialidades, além de permitir que as dificuldades ocasionais ou déficits possam ser superados.

\section{Deficiência Visual e Inclusão Escolar}

O termo inclusão refere-se ao acolhimento de todas as pessoas independente de cor, raça, religiáo, classe social, condiçóes físicas e psicológicas. Assim, como mencionam Moreira, Michels e Colossi (2006), a inclusão no âmbito escolar envolve o acolhimento no sistema de ensino a todas as pessoas. Isso não é algo recente, mas vêm sendo desenvolvido e percebido como uma necessidade desde o século passado, com vistas à garantia do direito de todos, independente das diferenças e livre de preconceitos, como menciona o autor abaixo:

Pode-se dizer que a discussão sobre inclusão, no sentido mais amplo, não é algo novo. Desde a primeira metade do século XX, com a aprovação da declaração dos Direitos Humanos em 1948, seus princípios já foram apresentados em formas de declarações e diretrizes políticas. (SOUZA, 2012, p. 12).

No que se refere à inclusão da criança com deficiência visual em escola regular, Batista (1998) traz uma revisão de literatura realizada por Bishop (1997) voltada para a situação dos Estados Unidos em relação aos primeiros esforços de inclusão constatando, entre outros, o fato de que a mera inserção do aluno na escola regular, sem preparação, raramente funciona. Assim é importante uma maior preparação dos professores, provimento de material pedagógico adequado e de providências para favorecer a interação entre colegas.

Em relação ao contexto brasileiro só na década de 1970, foi criado, no Ministério da Educação, o Centro Nacional de Educação Especial, com o propósito de coordenar a implementação de uma política de educação das pessoas com deficiência, incluindo nesse grupo os deficientes visuais. Autores como Souza e Santos (2010) também destacam que no Brasil essa política só veio se efetivar a partir da década de noventa. As mesmas autoras ressaltam que apesar da implantação no Rio de Janeiro do Imperial Instituto dos Meninos Cegos e o Instituto dos Surdos-Mudos, na segunda década do século XIX, a educação de pessoas com deficiência ainda não superou o problema básico da quantidade e da qualidade. 
Visto isso, alguns autores como Orrico, Canejo e Fogli (2009) assinalam a importância de açóes que possibilitem a superação de barreiras não somente estruturais, arquitetônicas ou comunicacionais, mas também de barreiras atitudinais, para que o processo de inclusão de alunos com deficiência visual em escolas regulares seja viável. Esses autores afirmam que a escolarização e educação da pessoa com algum tipo de deficiência, em particular da criança cega ou com baixa visão é possível, desde que sejam oferecidos meios necessários e vias alternativas à visão, para o desenvolvimento de suas potencialidades. É importante, nesse sentido que as pessoas acreditem na capacidade da criança, para além do estereótipo que permeia a deficiência, bem como suas inúmeras possibilidades de crescimento e desenvolvimento, principalmente no que se refere à aprendizagem.

Torna-se necessário um ambiente de desenvolvimento que não envolve somente a estrutura escolar, mas também o acolhimento e viabilização de oportunidades promovidas pela tríade família, escola e aluno, pois não se pode pensar em uma política de inclusão pautada exclusivamente em iniciativas individuais. Portanto, a educação inclusiva ainda é um desafio e ao se propor um trabalho voltado para crianças com deficiência visual, deve-se levar em conta, que cada criança é diferente e possui limitaçôes que podem ser inerentes ou não a sua deficiência. Por isso deve-se enfatizar que crianças com deficiência visual possuem muitas potencialidades e estas, se abordadas de forma efetiva, podem promover seu maior desenvolvimento. Sendo assim é importante que se supere a ideia de que incluir é somente matricular o aluno com algum tipo de deficiência na escola regular. É fundamental que tanto a escola como a comunidade promovam práticas que favoreçam o desenvolvimento desse aluno.

\section{Deficiência Visual, Interação Social e Habilidades Sociais}

Dentro da perspectiva de inclusão, uma temática de extrema relevância para favorecimento do processo inclusivo diz respeito às habilidades sociais de crianças cegas e seus pares. Nesse sentido, faz-se necessário tecer algumas consideraçôes sobre a importância do meio social, em termos das interaçôes sociais estabelecidas no contexto da escola bem como a respeito do repertório de habilidades sociais de crianças cegas. A relevância dessa temática para a inclusão está no fato de que é a partir da interação entre diferentes sujeitos que se estabelecem e desenvolvem processos de aprendizagem, como enfatiza Melo e Teixeira (2012, p.03) ao mencionar que "neste processo, o ser humano necessita estabelecer uma rede de contatos com outros seres humanos para incrementar e construir novos conceitos".

Nesse contexto diversos autores, como Roe (2008, apud FRANÇA-FREITAS; GIL, 2012), Pedrosa e Carvalho (2005), Davis; Setúbal e Espósito (1989) destacam como as interaçôes sociais podem contribuir para o desenvolvimento da criança e para auxiliar na superação das limitaçôes relacionadas à sua deficiência.

Para as crianças com deficiência visual, a interação com os outros é fundamental para superar algumas das limitaçóes de acesso visual que essas crianças experienciam, bem como para ajudá-las a fazer conexôes e desenvolver sua compreensão do mundo [...] 
crianças com deficiência visual precisam de oportunidades para interagir com uma ampla gama de colegas, incluindo aqueles com um elaborado repertório de habilidades sociais e de comunicação, pois esses colegas podem servir de modelos positivos e compensar alguns dos desafios criados pelo acesso limitado às informaçóes visuais [...]. (ROE, 2008 apud FRANÇA-FREITAS; GIL, 2012, p. 319).

Desse modo, assim como as interaçôes sociais são fundamentais para o desenvolvimento das crianças, é preciso fazer referência também à importância das habilidades sociais nesse contexto para o alcance de interaçôes sociais satisfatórias. As habilidades sociais consistem em "diversas classes de comportamentos sociais que permitem a uma pessoa usufruir de relaçôes reforçadoras, saudáveis e produtivas com os outros em qualquer situação e cultura”. (DEL PRETTE; DEL PRETTE, 2005, p. 31).

A respeito dessas variáveis ressalta-se que há um crescimento nos estudos da área de habilidades sociais e um interesse maior por parte de psicólogos, psiquiatras educadores, principalmente no que se refere à infância. Reitera-se ainda que "um repertório elaborado de habilidades sociais contribui decisivamente para relaçóes harmoniosas com colegas e adultos na infância" como afirmam Del Prette e Del Prette (2005, p. 16). Esses autores ainda enfatizam que habilidades de comunicação, expressividade e desenvoltura nas interaçóes sociais podem se reverter em amizade, respeito, status no grupo ou, facilitar uma convivência cotidiana mais agradável. Os mesmos autores destacam que a relevância das habilidades sociais para a qualidade de vida das crianças é citada em documentos de agências internacionais e nacionais de amparo à infância, como Organização Mundial da Saúde, Organização Pan-Americana de Saúde e Ministério da Saúde no Brasil.

Com relação às deficiências sensoriais, estudos de Del Prette e Del Prette (1999/2005), Freitas e Del Prette (2003), e Lopes (2004) evidenciam a importância das habilidades sociais na diminuição das dificuldades e limitações trazidas pela deficiência.

Deficiências visuais restringem o acesso a modelos e a aprendizagem por observação, podendo interferir tanto na discriminação dos sinais sociais mais sutis da expressão facial e corporal do interlocutor como na adequação do próprio comportamento (verbal e não verbal), às demandas não verbais do ambiente. Essas dificuldades parecem estar na base das avaliaçóes negativas do desempenho social de crianças e adolescentes com deficiência visual. (DEL PRETTE; DEL PRETTE, 2005, p. 27).

Caballo et. al. (1997 apud MAIA; DEL PRETTE; FREITAS, 2008) destacam que, de acordo com a literatura da área e as pesquisas realizadas, as principais dificuldades apresentadas por pessoas com deficiência visual, com relação aos temas habilidades sociais e deficiência visual são referentes à menor frequência de interação com seus pares, sejam eles videntes ou não; déficits na emissão e decodificação de comportamentos não verbais; dificuldades em iniciar e manter brincadeiras; maior isolamento social e problemas de adaptação social. 
A partir do que foi mencionado, fica evidente que a aprendizagem de habilidades sociais é de grande importância para a superação de dificuldades ou déficits em crianças que apresentam algum tipo de deficiência, inclusive crianças com deficiência visual. Nesse sentido, tendo em vista à carência de estudos e modelos de intervenção específicos que abordem a importância de um repertório bem elaborado de habilidades sociais em crianças cegas, no contexto da educação inclusiva em escola regular, o presente estudo aborda essa temática. Estudos como os de Del Prette e Del Prette (1999), de Freitas e Del Prette (2003), e de Lopes (2004) apontam a importância de habilidades sociais em relação às deficiências sensoriais. Embora essas variáveis não solucionem o problema orgânico, podem pelo menos amenizar seus efeitos psicológicos, especialmente na comunicação com pessoas sem deficiência, a fim de melhorar assim a condição de vida e socialização (DEL PRETTE; DEL PRETTE, 2005 apud CARDOZO; SOARES, 2010).

Diante disso, o presente artigo objetiva analisar o repertório de habilidades sociais e a inclusão escolar de uma criança cega. Para isso foi importante caracterizar o repertório de habilidades sociais dessa criança, identificar as classes de habilidades sociais mais desenvolvidas, como também caracterizar a interação social da criança cega no contexto da educação inclusiva.

\section{Método}

\section{Delineamento}

No presente estudo foi adotada uma pesquisa qualitativa de delineamento descritivo, através de multimétodos onde foram realizados estudo de caso, observação por meio de filmagens, aplicação de um instrumento de medida de habilidades sociais com a mãe e duas professoras, além do uso de um Diário de Campo para anotaçáo do que aconteceu de mais relevante durante as visitas à escola.

\section{Participantes}

Participou deste estudo uma criança cega (C) do sexo feminino com 11 anos de idade, estudante do $5^{\circ}$ ano de uma escola regular e seus colegas videntes. Segundo relatos da mãe, $\mathrm{C}$ nasceu prematura de 6 meses e enxergava ao nascer, no entanto devido ao longo período que passou na incubadora houve um deslocamento da retina, o que ocasionou a cegueira. A criança estudava nessa instituição de ensino desde 2010 ( $1^{\circ}$ ano), anteriormente ela havia frequentado uma escola de educação especial. A escola atual que $\mathrm{C}$ estuda faz parte da rede estadual do ensino da cidade de Aracaju, Sergipe. Funciona nos turnos matutino e vespertino e atende a crianças com e sem algum tipo de deficiência intelectual e/ou sensorial.

Em relação às crianças com deficiência visual, a escola possui alunos com cegueira total e baixa visão, matriculados no ensino fundamental, sendo seis alunos com cegueira total. Vale mencionar que somente essa criança foi escolhida devido a sua idade de 11 anos. A instituiçáo possui uma sala de recursos adaptada para atender as crianças com deficiências, onde lá elas realizam as atividades solicitadas pelos professores. Participaram como informantes a máe da criança e as duas professoras (uma da sala de recursos e da sala de aula regular). 


\section{Instrumentos}

Foi utilizado o SSRS-BR ${ }^{2}$ (Social Skills Rating System) que é um instrumento voltado para crianças de $1^{\circ}$ ao $5^{\circ}$ ano, e é composto por três versôes: para professores, contendo 45 questóes que avaliam as habilidades sociais e seu grau de importância, comportamentos problemáticos e a posição da criança em indicadores de sua competência acadêmica; uma versão para os pais, que contém 38 questôes para avaliação das habilidades sociais e comportamentos problemáticos; e uma para a própria criança. As alternativas de resposta estão dispostas em uma escala que varia de zero a dois $(0$ = nunca, 1 = algumas vezes, 2 = muito frequente). No presente estudo foi adotada somente a versão para pais e professores, uma vez que a condição da criança não permitiria preencher a versão de autorrelato do instrumento.

\section{Procedimentos de coleta de dados}

A coleta de dados foi realizada em três semanas, com seis visitas a escola, duas vezes em cada semana. As observaçôes através de filmagens e registro das situações de interação da criança foram realizadas em um contexto onde ela estava livre, como por exemplo, no horário do intervalo e na aula de educação física, com duração de 20 minutos cada observação. Vale destacar que foi feito um período de adaptação das crianças à presença das pesquisadoras e à câmera filmadora, deixando-a inicialmente desligada para que sua presença não interferisse ou alterasse a rotina das crianças.

É importante mencionar que para obtenção das informações empíricas, o estudo foi submetido ao Conselho de Ética, sendo atendidas todas as exigências legais. Foi entregue também o Termo de Consentimento Livre e Esclarecido aos pais da criança que participou da pesquisa para consentimento da participação do (a) filho (a) sendo garantido o sigilo total das informaçôes coletadas e o anonimato do participante.

Foi aplicado com a mãe e duas professoras (da sala de aula regular e da sala de aula de recursos) o inventário SSRS-BR ${ }^{2}$. Vale frisar que no presente estudo só foram avaliadas as habilidades sociais da criança, já que este é um dos propósitos da pesquisa.

\section{Tratamento e análise dos dados}

O procedimento de tratamento dos dados teve início com o recorte dos episódios de interação na hora do intervalo e na aula de educação física. Adotou-se neste estudo a definição operacional de interação social apresentada por Mello e Teixeira (2012) como a forma de as pessoas se relacionarem e estabelecerem contatos nos grupos as quais estão inseridas. Os critérios para identificação dos episódios foram: (a) toda iniciativa de interação que envolvesse a criança cega ou vidente; (b) todo término de interação que envolvesse a criança cega ou vidente; (c) todo início e término de interação da criança cega com os professores.

Foram organizados roteiros para transcrição das observações relacionados às iniciativas e términos das interaçóes, como também foram observados quais desses comportamentos expressos pela criança favoreciam a capacidade da criança em lidar com as situaçôes do seu dia-a-dia, inclusive no que se referia às interaçôes eficazes com os outros. 
Em relação à aplicação do inventário SSRS-BR² com a mãe e as professoras, ressalta-se que essas foram orientadas quanto ao preenchimento do questionário. Ademais as pesquisadoras permaneceram presentes para monitorar o processo e esclarecer dúvidas que surgissem. As respostas obtidas através do instrumento foram categorizadas e analisadas de acordo com as subescalas de habilidades sociais da criança, que estáo discriminadas a seguir de acordo com os fatores: F1- equivalente à responsabilidade; F2- autocontrole; F3-afetividade/cooperação (para a versão com os pais) e assertividade/desenvoltura social (versão com os professores); F4- desenvoltura social (para os pais) e cooperaçáo/afetividade (para os professores); F5-civilidade (somente para a versáo com os pais). Tais fatores são definidos de acordo com Del Prette e Del Prette (2005) da seguinte forma: Responsabilidade (F1) referente a pedir ajuda aos outros, solicitar permissão para utilizar objetos de colegas, identificar a pessoa certa para informar sobre algum incidente etc; Autocontrole (F2) referente às habilidades que demonstrem ajustamento emocional, responder apropriadamente a críticas, lidar com situações de conflito ou pressão, entre outros; Afetividade/cooperação (F3) envolve ajuda aos outros, compartilhar materiais, seguir regras e instruçôes, habilidades que demonstrem positividade com os colegas; Assertividadeldesenvoltura social (F3/ F4) incluem habilidades expressivas, pedir informaçóes, apresentar-se e reagir a açóes injustas de outros, convidar para atividades etc; e Civilidade (F5) habilidade que compreende o cumprimento às pessoas, fazer e aceitar elogios, expressáo de solidariedade e companheirismo ou polidez social. Foi realizado o somatório de tais fatores, convertidos os valores dos escores de acordo com os percentis para o sexo feminino, conforme a avaliação dos pais e dos professores. Posteriormente foi descrito e analisado conforme a posiçáo percentil dos escores (total e fatoriais) da criança, para as subescalas de habilidades sociais do SSRS-BR ${ }^{2}$.

\section{Resultados e discussão}

De acordo com os dados obtidos através das filmagens no contexto de interação da criança, foram consideradas as características das iniciativas, do recebimento das iniciativas e do término das interaçôes com as outras crianças videntes e com as professoras. Nesse contexto, verificou-se que a criança interagiu com maior frequência com as professoras e com os colegas da sala de recursos. O número de iniciativas de interaçôes com as crianças videntes foi bem menor, sendo que a criança cega demonstrava rejeitar as iniciativas de interação das crianças videntes. Quando os colegas videntes se aproximavam a criança cega afastava-se ou ignorava quando chamada para brincar, como fica demonstrado nas Tabelas 1 e 2 abaixo. No horário do intervalo/recreio a criança cega permaneceu a maior parte do tempo na sala de recursos e se recusava a brincar com as colegas videntes. 
Tabela 1 - Roteiro de Filmagem: Contexto de interação da criança cega (C) na aula de Educação Física.

\begin{tabular}{|c|c|c|c|c|c|c|}
\hline & \multicolumn{2}{|c|}{ Criança Cega (C) } & \multicolumn{2}{|c|}{ Criança Vidente } & \multicolumn{2}{|c|}{ Professor } \\
\hline $\begin{array}{c}\text { Aula de } \\
\text { Educaçáo de } \\
\text { Física }\end{array}$ & $\begin{array}{l}\text { Iniciativa } \\
\text { de } \\
\text { interação }\end{array}$ & $\begin{array}{l}\text { Término } \\
\text { de } \\
\text { Interação }\end{array}$ & $\begin{array}{l}\text { Iniciativa } \\
\text { de } \\
\text { interação }\end{array}$ & $\begin{array}{l}\text { Término } \\
\text { de } \\
\text { Interação }\end{array}$ & $\begin{array}{l}\text { Iniciativa } \\
\text { de } \\
\text { interação }\end{array}$ & $\begin{array}{l}\text { Término } \\
\text { de } \\
\text { Interação }\end{array}$ \\
\hline \multirow{7}{*}{$\begin{array}{l}\text { Tempo de } \\
\text { duraçáo da } \\
\text { interaçáo }\end{array}$} & & & X (40s) & $X(1 \min )$ & & \multirow{7}{*}{$X(2 \mathrm{~min})$} \\
\hline & & $\mathrm{X}(40 s)$ & $X(1 \min )$ & & & \\
\hline & & $X(20 s)$ & $X(1 \min )$ & & & \\
\hline & $\mathrm{X}(3 \min )$ & $X(5 s)$ & $X(15 s)$ & & & \\
\hline & & $X(1 \min )$ & $X(1 \min )$ & & & \\
\hline & & $X(3 \min )$ & $X(3 \min )$ & & & \\
\hline & & $X(1 \min )$ & & & $X(1 \min )$ & \\
\hline $\begin{array}{c}\text { Total: } \\
20 \mathrm{~min}\end{array}$ & $3 \mathrm{~min}$ & $6 \min 5 s$ & $6 \min 55 s$ & $1 \mathrm{~min}$ & $1 \mathrm{~min}$ & $2 \mathrm{~min}$ \\
\hline
\end{tabular}

Tabela 2 - Roteiro de Filmagem: Contexto de interação da criança cega (C) no recreio/intervalo

\begin{tabular}{|c|c|c|c|c|c|c|}
\hline \multirow[b]{2}{*}{$\begin{array}{r}\text { Intervalo } \\
\text { (recreio) }\end{array}$} & \multicolumn{2}{|c|}{ Criança Cega $(C)$} & \multicolumn{2}{|c|}{ Criança Vidente } & \multicolumn{2}{|c|}{ Professor } \\
\hline & $\begin{array}{l}\text { Iniciativa } \\
\text { de } \\
\text { interação }\end{array}$ & $\begin{array}{l}\text { Término } \\
\text { de } \\
\text { interação }\end{array}$ & $\begin{array}{l}\text { Iniciativa } \\
\text { de } \\
\text { interação }\end{array}$ & $\begin{array}{c}\text { Término } \\
\text { de } \\
\text { interação }\end{array}$ & $\begin{array}{c}\text { Iniciativa } \\
\text { de } \\
\text { interação }\end{array}$ & $\begin{array}{c}\text { Término } \\
\text { de } \\
\text { interação }\end{array}$ \\
\hline \multirow{12}{*}{$\begin{array}{c}\text { Tempo de } \\
\text { duraçáo } \\
\text { da } \\
\text { interaçáo }\end{array}$} & & & $\mathrm{X}(30 s)$ & $X(10 s)$ & & \\
\hline & $\mathrm{X}(2 \mathrm{~min})$ & $\mathrm{X}(2 \mathrm{~min})$ & & & & \\
\hline & & & & & $X(10 s)$ & $\mathrm{X}(10 \mathrm{~s})$ \\
\hline & $X(1 \mathrm{~min})$ & & & & & $X(3 \min )$ \\
\hline & $X(1 \min )$ & & & $X(1 \mathrm{~min})$ & & \\
\hline & $\mathrm{X}(40 s)$ & & & & & $X(20 s)$ \\
\hline & & $X(1 \min )$ & $\mathrm{X}(2 \mathrm{~min})$ & & & \\
\hline & X (20s) & & & X (10s) & & \\
\hline & $X(2 \min )$ & & & & $\mathrm{X}(1 \mathrm{~min})$ & \\
\hline & & $X(15 s)$ & $X(20 s)$ & & & \\
\hline & & $X(10 s)$ & & & $\mathrm{X}(30 \mathrm{~s})$ & \\
\hline & $\mathrm{X}(40 s)$ & & & & & $X(15 s)$ \\
\hline $\begin{array}{c}\text { Total: } 20 \\
\text { min } 40 \mathrm{~s}\end{array}$ & $7 \min 40 s$ & $3 \min 25 s$ & $2 \min 50 s$ & $1 \min 20 s$ & $1 \min 40 s$ & $3 \min 45 s$ \\
\hline
\end{tabular}


A Tabela 1 evidencia o que foi mencionado anteriormente, ou seja, notou-se que na sala de aula regular as crianças videntes iniciavam com maior frequência as interaçôes com $\mathrm{C}$ (criança cega), e geralmente era $\mathrm{C}$ que terminava a interação. Verificou-se que as iniciativas de $\mathrm{C}$ foram direcionadas com maior frequência à professora da sala de aula regular do que aos pares videntes.

$\mathrm{Na}$ Tabela 2 observa-se que a criança cega teve mais iniciativas de interação, porém novamente essa interaçáo foi mais frequente com a professora da sala de recursos do que com as crianças videntes, já que geralmente ela ficava na hora do intervalo/recreio na sala de recursos e saía sozinha, sem bengala, para comprar o lanche e voltava.

Houve maior frequência de iniciativas de interação de $\mathrm{C}$ no horário do intervalo/recreio, porém a maior parte com a professora da sala de recursos. $\mathrm{Na}$ aula de Educação Física as iniciativas de interaçáo partiram das crianças videntes, enquanto os términos de interação partiram de $\mathrm{C}$, não foi observada nessa aula, nenhuma iniciativa de interaçáo por parte de C com seus colegas videntes, somente com a professora.

Após as observações relacionadas à interação da criança foi aplicado o inventário SSRS-BR ${ }^{2}$ na mãe da criança e nas duas professoras (da sala de recursos e da sala de aula regular). Os dados obtidos no geral tanto na versão com a mãe, quanto com as professoras, demonstram que $\mathrm{C}$ apresentava um repertório de habilidades sociais médio inferior (percentil 26-35), com resultados abaixo da média em grande parte dos itens, sendo este um indicativo de necessidade de Treinamento de Habilidades Sociais. Os dados revelaram que os menores escores estáo relacionados aos fatores F3 que diz respeito Afetividade/Cooperação (para a versão com os pais) e Assertividade/ Desenvoltura Social (para a versão com os professores) e F4, que diz respeito à Desenvoltura Social, escores medianos relacionados à Civilidade (F5) e Autocontrole (F2). Foram obtidos maiores escores no fator Responsabilidade (F1).

Os resultados obtidos na caracterização do repertório de habilidades sociais da criança cega corroboram com estudos anteriores de Del Prette e Del Prette (2005), os quais fazem referência à importância das habilidades sociais para a socialização e para a manutençáo de relaçóes harmoniosas com os colegas. Esses autores ainda reforçam que habilidades de desenvoltura, cooperação, comunicação e expressividade facilitam a convivência cotidiana mais agradável.

Como foi percebido $\mathrm{C}$ apresentava alguns comportamentos que dificultavam sua interação, principalmente no que se refere às crianças videntes, tais como: recusava ajuda da colega para arrumar o cabelo; ignorava quando uma colega vidente a chamava para brincar na hora do intervalo; recusava ajuda do colega vidente para pegar um classificador na mochila. Tais comportamentos refletiam os déficits que ela apresentava em algumas classes de habilidades sociais e que são importantes para socialização, como: afetividade, cooperação, assertividade e desenvoltura social.

Nessa linha de raciocínio, pesquisas de Caballo et. al (1997 apud MAIA; DEL PRETTE; FREITAS, 2008) enfatizam que as principais dificuldades apresentadas 
por pessoas com deficiência visual com relação às habilidades sociais são referentes à menor frequência de interação com seus pares, sejam eles videntes ou não; dificuldades em iniciar e manter brincadeiras; maior isolamento social e problemas de adaptação social. Esse argumento é reforçado pelas observaçôes feitas no presente estudo, no qual a criança apresentou uma baixa frequência de interação de $\mathrm{C}$ com as outras crianças videntes, principalmente nas aulas de educação física, que envolveram mais brincadeiras.

Vale mencionar que foi observado e relatado tanto pela genitora como pelas professoras, que a criança demonstrava grandes anseios na busca por autonomia. Destaca-se que esse comportamento é importante, porém acabava por gerar dificuldades com relação à aceitação de críticas e de suas limitaçôes, como também na interação com as outras crianças, uma vez que ela recusava ajuda sem agradecer ao outro a iniciativa em se dispor a ajudá-la. Isso ficava evidenciado em algumas situaçóes, como por exemplo: recusava usar bengala, tanto em casa, como na escola, e acabava se batendo em objetos; rejeitava ajuda para pegar o lanche; rejeitava e ficava chateada quando os colegas videntes tentavam arrumar seu cabelo; recusava ajuda para guardar seu material escolar.

No entanto é importante frisar que a criança não apresentava problemas quanto a questóes de aprendizagem. Ela era atenta e participava ativamente das aulas, isso revela comportamentos relacionados à subescala da habilidade de responsabilidade. As professoras incentivavam a sua participação em sala, como também os colegas videntes demonstravam iniciativa de auxiliá-la nas atividades, nas dificuldades de locomoção e respeitavam suas limitaçôes. Observou-se também que as professoras tentavam envolver a turma em questôes relacionadas à inclusão, através de atividades e brincadeiras que estimulassem o respeito e a participação das crianças com deficiências. Contudo foi observado que $\mathrm{C}$ recusava ajuda em algumas situaçóes e não demonstrava ter interesse em se envolver em atividades com as crianças videntes, tais aspectos podem ter favorecido o isolamento social da criança.

Nesse sentido, foi percebido que a escola tentava criar práticas que favorecessem tanto a inclusão do aluno com deficiência, uma vez que existiam outras crianças com necessidades educacionais especiais, quanto o esclarecimento dos demais colegas com relação às deficiências, fossem elas físicas, sensoriais ou intelectuais. Tal aspecto é de suma importância, como enfatiza estudos de Orrico, Canejo e Fogli (2009), os quais assinalam que para a viabilização no processo de inclusão de alunos com deficiência visual é importante a promoção de açôes que removam tanto as barreiras estruturais quanto atitudinais.

Desse modo, verificou-se que a escola onde foi realizada a pesquisa tinha uma estrutura física adequada para atender às crianças com deficiências, como também incentivava o acolhimento e a participação da família junto à escola com atividades que tentavam estimular a participação da criança, a fim de promover a interação social da criança cega com seus pares videntes. Em contrapartida $C$ apresentava déficits em algumas classes de habilidades sociais o que acabava por interferir na sua relação com os colegas e consequentemente no processo de inclusão. 


\section{Considerações finais}

Os dados obtidos através desse estudo confirmam, em sua maioria, os achados encontrados em outras pesquisas de Del Prette e Del Prette (2005), Caballo et. al (1997 apud MAIA; DEL PRETTE; FREITAS, 2008) no que se refere aos déficits em algumas classes de habilidades sociais e sua relação com as dificuldades de interação da criança cega com as videntes.

É preciso compreender que apesar da escola desenvolver práticas inclusivas, a criança apresentava dificuldades em manter relaçóes mais próximas com os videntes. Não foi percebido iniciativas de aproximações da criança cega em relação aos colegas videntes. Supóe-se que ela tentava superar as barreiras impostas pela deficiência sozinha, sem a ajuda dos outros, isso pode ser percebido pelo fato dela ter se incomodado com o auxílio do outro em certas situaçóes. Apesar dessa autonomia e independência ser importante para o desenvolvimento da criança cega, a forma como essa se comportava nessas situaçôes gerava consequências negativas relacionadas à relação com os colegas bem como favorecia ao isolamento social.

Nesse sentido é importante que estudos voltados para a promoção de habilidades sociais sejam desenvolvidos com crianças deficientes visuais, para que se ampliem a formulação de atividades de intervenção que possam contribuir para promover a interação social entre crianças cegas e videntes no contexto de uma escola inclusiva, bem como o desenvolvimento do repertório de habilidades sociais dessas crianças.

De modo geral, é preciso destacar que os resultados do presente estudo não permitem generalizaçôes, em função de a amostra ser composta por apenas um indivíduo. No entanto, observações e aspectos importantes foram destacados acerca das habilidades sociais da criança cega, seu comportamento no contexto de interação social no ambiente escolar. Propóe-se a realização de pesquisas futuras dedicados à elaboração de práticas pedagógicas que possam estimular o desenvolvimento de habilidades e a promoção de interaçôes sociais satisfatórias no contexto de sala de aula.

\section{Referências}

BATISTA, C. G. Crianças com deficiência visual: como favorecer sua escolarização? Temas psicol. Ribeirão Preto, v. 6, n. 3, dez. 1998.

BATISTA, C. G. Formação de Conceitos em Crianças Cegas: Questôes Teóricas e Implicaçôes Educacionais. Psicologia: Teoria e Pesquisa, Brasília, jan./abr., 2005, v. 21, n. 1, p. 07-15.

BISHOP, V. E. Educational inclusion: premise, practice and promise. Anais da Xth World Conference do ICEVI (International Council for Education of People with visual impairment), 1997.

COSTA, C. L.; DEL PRETTE, A. Estudo comparativo de observação de habilidades sociais de gêmeas com e sem deficiência visual. Revista Educaçáo Especial, Santa Maria, v. 25, n. 42, p. 75-88, jan./abr. 2012.

DAVIS, C.; SETÚBAL, M. A.; ESPÓSITO, Y. L. Papel e valor das interaçóes sociais em sala de aula. Cad. Pesq., São Paulo, v. 71, p. 49-54, 1989.

DEL PRETTE, A. \& DEL PRETTE, Z. A. P. Teoria das Inteligências Múltiplas e Treinamento de Habilidades Sociais. Doxa: Estudos de Psicologia e Educação,v. 5, p. 51-64, 1999.

DEL PRETTE, Z. A. P.; DEL PRETTE, A. Psicologia das habilidades sociais: Terapia, Educação e Trabalho. Petrópolis: Vozes, 1999.

Psicologia das habilidades sociais na infância: Teoria e prática. Petrópolis: Vozes, 2005. 
FERREIRA, B. C.; DEL PRETTE, Z. A. P. Programa de Expressividade Facial de Emoçôes e Habilidades Sociais de Crianças Deficientes Visuais e Videntes. Psicologia: Reflexáo e Crítica, v. 26, n. 2, p. 327-338, 2013.

FRANCA-FREITAS, M. L. P.; GIL, M. S. Interação social de crianças cegas e de crianças videntes na educaçáo infantil. Psicol. Esc. Educ., Maringá, v. 16, n. 2, Dec. 2012.

FREITAS, L. C., DEL PRETTE, Z. A. P. Habilidades sociais de crianças com diferentes necessidades educacionais especiais: Avaliação e implicaçóes para intervenção. Avances em Psicología Latinoamericana, v. 31, n. 2, p. 344-362, 2013.

Habilidades sociais de crianças com diferentes necessidades educacionais especiais: Avaliaçẫo e implicações para intervenção. Av. Psicol. Latinoam., Bogotá, v. 31, n. 2, ago. 2013.

FREITAS, M. G; DEL PRETTE, Z. A. P. Habilidades sociais de crianças deficientes visuais: Programa de intervenção com mães. In: ABPMC (Org.). Anais do XII Encontro Brasileiro de Psicoterapia e Medicina Comportamental, Londrina, p. 32-33, 2003.

HORA, V. S. Educação Inclusiva nas escolas privadas de Aracaju: um estudo de caso. Anais do: V Colóquio Internacional: Educação e Contemporaneidade. São Cristovão, p. 1-10, 2011.

LOPES, C. S. Comparando habilidades de criança cega e vidente: um estudo de caso com gêmeas idênticas. Dissertação de Mestrado. Programa de pós-graduação em Educação Especial. Universidade Federal de São Carlos, 2004.

MAIA, J. M. D.; DEL PRETTE, A.; FREITAS, L. C. Habilidades sociais de pessoas com deficiência visual. Rev. bras. ter. cogn., Rio de Janeiro, v. 4, n. 1, jun. 2008.

MELLO, E. F. F.; TEIXEIRA, A. C. A interaçấo social descrita por Vigotski e a sua possível ligação com a aprendizagem colaborativa através das tecnologias em rede. In: Anais do Seminário de Pesquisa e Educação da Regiāo Sul - IX ANPED SUL, 2012, p. 1-15.

MINISTÉRIO DA EDUCAÇÃO. Programa de Capacitaçáo de Recursos Humanos do Ensino Fundamental: deficiência visual. Vol. 1 fascículos I - II - III / Marilda Moraes Garcia Bruno, Maria Glória Batista da Mota, colaboração: Instituto Benjamin Constant. Brasília: Secretaria de Educação Especial, 2001.

MINISTÉRIO PÚBLICO FEDERAL. O Acesso de Alunos com Deficiência às Escolas e Classes Comuns da Rede Regular. $2^{\text {a }}$ ed. Fundação Procurador Pedro Jorge de Melo e Silva (Org.). Brasília: Procuradoria Federal dos Direitos do Cidadáo, 2004.

MONTILHA, R. C. et al. Percepçôes de escolares com deficiência visual em relação ao seu processo de escolarização. Paidéia (Ribeirão Preto), Ribeirão Preto, v. 19, n. 44, Dec. 2009.

MOREIRA, H. F.; MICHELS, L. R.; COLOSSI, N. Inclusão educacional para pessoas portadoras de deficiência: um compromisso com o ensino superior. Escritos educ. 2006, v. 5, n. 1, p. 19-25. ISSN 16779843. Disponível em: <http://pepsic.bvsalud.org/pdf/eeduc/v5n1/v5n1a04.pdf>. Acesso em: maio 2015.

NOBRE et. al. Baixa visão e reabilitação: conhecimentos de residentes de oftalmologia. Medicina, Ribeirão Preto, v. 39, n. 2, p. 253-259, abr./jun. 2006.

NUNES, S.; LOMÔNACO, J. F. B. O aluno cego: preconceitos e potencialidades. Psicol. Esc. Educ., Paraná, 2010, v. 14, n.1, p. 55-64.

ORRICO, H.; CANEJO, E.; FOGLI, B. Uma reflexão sobre o cotidiano escolar de alunos com deficiência visual em classes regulares. In: GLAT, R. Educaçáo Inclusiva: Cultura e cotidiano escolar. Rio de Janeiro: 7Letras, 2009. Cap. 7, p. 116-136.

PEDROSA, M. I.; CARVALHO, A. M. A. Análise qualitativa de episódios de interação: uma reflexão sobre procedimentos e formas de uso. Psicologia: Reflexão e Crítica, v. 18, n. 3, p. 431-442, 2005.

ROE, J. Social inclusion: meeting the socio-emotional needs of children with vision needs. British Journal of Visual Impairment, v. 26, n. 2, 2008, p. 147-158.

SACKS, S. Z. The social development of visually impaired children: A theoretical perspective. In: SACKS, S. Z.; KEKELIS, L. S.; GAYLORD-ROSS, R. J. (Orgs.). The development of social skill by blind and visually impaired student: Exploratory studies and strategies (2 ed.) (p. 3-11). New York: American Fundation for Blind, 1997.

SANTOS, A. C.; PEREIRA, J. L. C. O Retrato de uma experiência inclusiva na Área da Deficiência Visual. In: Anais do XI CONGRESSO NACIONAL DE EDUCAÇÃO EDUCERE, Curitiba, 2013. 
Marina Pereira de Souza - Priscila Alcântara Bezerra Silva - Maria Luiza Pontes de França-

Freitas - Graziela Maria da Silva Gatto

SILVA, G. C. Aluno cego no ensino regular: possibilidades e limitaçôes. Trabalho de Conclusão de Curso, Universidade Extremo Sul Catarinense, UNESC. Criciúma, 2010.

SILVA, M. M. P.; SILVA, M. C. V. Revista Nova Escola e a inclusão de alunos com deficiência no sistema regular de ensino. In: Anais do IX ANPED SUL - SEMINÁRIO DE PESQUISA EM EDUCAÇÃO DA REGIÂO SUL, Universidade de Caxias do Sul, 2012.

SOUZA, R. C. S. Educaçáo especial do século XIX ao início do século XX: cuidar e educar para civilizar. 2009. 196. f. il. Tese (Doutorado) - Faculdade de Educação, Universidade Federal da Bahia, Salvador, 2009.

Educaçáo Inclusiva e deficiência visual. Aracaju: Editora Criaçăo, 2012.

SOUZA, V. R. M.; SANTOS, A. C. N. Inclusão, ensino e pesquisa na Universidade Federal de Sergipe. In: FILHO, T. A. G.; MIRANDA, T. G. O professor e a educação inclusiva: formação práticas e lugares. Salvador: EDUFBA, 2012, p. 461-478, 2010.

\section{Correspondência}

Maria Luiza Pontes de França Freitas - Universidade Federal do Rio Grande do Norte, Escola de Ciências e Tecnologia. AC Universidade Federal do Rio Grande do Norte, Lagoa Nova, CEP: 59078-970 - Natal, Rio Grande do Norte - Brasil.

E-mail: maryna_ps@hotmail.com - alcantaraprii@gmail.com - mluizapf@yahoo.com.br - grazielagatto@hotmail.com

Recebido em 16 de outubro de 2015

Aprovado em 07 de abril de 2016 